\title{
Editorial
}

\section{Preeclampsia: A Diagnosis-Nondiagnosis That Is Too Easily Made: The Case of Primary Hyperaldosteronism}

\author{
Giorgina Barbara Piccolia, b Claudia Mannucci ${ }^{a, c}$ \\ aNéphrologie, Centre Hospitalier Le Mans, Le Mans, France; ${ }^{b}$ Department of Clinical and \\ Biological Sciences, Università di Torino, Torino, Italy; ${ }^{c}$ Nephrology Service, Università di \\ Pisa, Pisa, Italy
}

After decades in which the major medical textbooks reported with slightly different wordings that preeclampsia (PE) in pregnancy is a transitory kidney disease ultimately cured when the mother delivers, we are finally acknowledging that PE is neither always transitory nor systematically cured and that it may be both the herald of future diseases of the kidney and the cardiovascular system and the epiphenomenon of an underlying disease, as the interesting and well-presented case series published here demonstrates [1-3]. While the number of systematic reviews, large-population studies, and long-term registry data are multiplying and most of them conclude with a generic statement that future studies, actions, and programs are needed, few if any changes are taking place in real-life clinical practice [4].

The result of this dangerous combination of minimalism (PE is a self-healing disorder), lack of interdisciplinary collaboration (the pragmatic obstetrician holding that "nephrologists make things too complicated," while the cultivated nephrologist retorts that "obstetricians oversimplify"), short-sightedness, and common alibis (no time to see all these women after a PE episode, someone else should do it ...) is that women who have already had a stressful and occasionally life-threatening episode of PE lose a precious occasion to receive a timely diagnosis of a potentially curable disease.

The series reported here is a clear example of how pregnancy is a valuable but often missed occasion for diagnosis of a potentially serious disease: of the 14 patients described, only 3 were diagnosed as having primary hyperaldosteronism within 1 year from the discovery of hypertension, while in 8 the interval was 5 years or more (up to 12 years). Perhaps even more interestingly, hypertension was diagnosed (or first appeared) in preg- 
Table 1. Two examples of complex presentation of primary hyperaldosteronism in pregnancy

\begin{tabular}{|c|c|c|}
\hline & Case 1 & Case 2 \\
\hline Age, years & 36 & 36 \\
\hline Origin & African & African \\
\hline BMI pre-pregnancy, kg/m² & 39 & 32 \\
\hline Known hypertension & No & Yes, after a first PE episode \\
\hline Signs and symptoms & Hyperemesis, tachycardia & Headache \\
\hline $\mathrm{BP}$ in pregnancy, mm $\mathrm{Hg}$ & $\begin{array}{l}\text { Normal-high at } 25 \mathrm{GW} \text {; not systemati- } \\
\text { cally controlled until delivery }\end{array}$ & $\begin{array}{l}\text { On the average } \mathbf{1 5 0} / \mathbf{9 0} \text {, with some peaks at } \\
\text { 24-h BP monitoring }\end{array}$ \\
\hline $\mathrm{K}$ in pregnancy (min-max), mEq/L & 2.7-3.6 & $3.4-4.3$ \\
\hline $\mathrm{HCO}_{3}{ }^{-}$(min-max), mmol/L & $19-25$ & $21-25$ \\
\hline Gestational diabetes & Yes & No \\
\hline Proteinuria, g/24 h (max) & 0.48 & 0.84 \\
\hline Diagnosis in pregnancy & $\begin{array}{l}\text { Hypokalemia due to hyperemesis, mild } \\
\text { pregnancy-induced proteinuria }\end{array}$ & $\begin{array}{l}\text { Severe PE superimposed on chronic } \\
\text { hypertension, with severe intrauterine } \\
\text { growth restriction }\end{array}$ \\
\hline Week of delivery & 39 (vaginal delivery) & $\begin{array}{l}27 \text { (CS section in the presence of inversion of } \\
\text { umbilical blood flow, at Doppler imaging) }\end{array}$ \\
\hline Baby's weight, g & 3,470 & 555 \\
\hline Centile & 59 & 2 \\
\hline Outcome (child) & $\begin{array}{l}\text { Hospital discharge after birth; normal } \\
\text { development }\end{array}$ & $\begin{array}{l}\text { Neonatal intensive care unit for } 5 \text { months; } \\
\text { apparently normal psychomotor } \\
\text { development, but frequent hospitalization for } \\
\text { infectious problems }\end{array}$ \\
\hline \multicolumn{3}{|l|}{ Hospital discharge } \\
\hline Time point & After delivery & After delivery \\
\hline BP, mm Hg & In range (no treatment) & $130 / 80$ \\
\hline $\mathrm{K}, \mathrm{mEq} / \mathrm{L}$ & 3.1 (with oral supplementation) & 4.3 (no supplementation) \\
\hline Proteinuria, g/24 h & 0.24 & 0.75 \\
\hline Treatment & Potassium chloride $600 \mathrm{mg}$ & $\begin{array}{l}\text { Nicardipine } 50 \text { mg twice daily; labetalol } 200 \\
\text { mg }\end{array}$ \\
\hline \multicolumn{3}{|l|}{ New referral } \\
\hline $\mathrm{BP}, \mathrm{mm} \mathrm{Hg}$ & $205 / 130$ without treatment & $\mathbf{2 0 0 / 1 0 0}$ with occasional treatment \\
\hline $\mathrm{K}, \mathrm{mEq} / \mathrm{L}$ & 3.1 (with supplementation) & 3.2 (without supplementation) \\
\hline Proteinuria, g/24 h & 0.24 & 0.26 \\
\hline Aldosterone, pg/mL & 160 & 185 \\
\hline Renin, mIU/L & 1.9 & 3.3 \\
\hline Aldosterone/renin ratio (n.v. <64) & 89 & 103 \\
\hline Antihypertensive treatment & Ramipril $5 \mathrm{mg}$; spironolactone $25 \mathrm{mg}$ & $\begin{array}{l}\text { Nicardipine } 50 \text { mg twice daily; enalapril } 20 \\
\text { mg; spironolactone } 25 \mathrm{mg}\end{array}$ \\
\hline $\mathrm{BP}$ after 1 week of treatment, $\mathrm{mm} \mathrm{Hg}$ & $150 / 90$ with some peaks at $180 / 100$ & $140 / 90$ with peaks at $170 / 110$ \\
\hline Imaging data & $\begin{array}{l}\text { CT scan: probable adenoma, surgical } \\
\text { workup ongoing }\end{array}$ & $\begin{array}{l}\text { CT scan: no clear adenoma; possible unilateral } \\
\text { hyperplasia; further workup ongoing }\end{array}$ \\
\hline
\end{tabular}

BMI, body mass index; BP, blood pressure; GW, gestational week; K, serum potassium; CT, computed tomography. 
Piccoli and Mannucci: Primary Hyperaldosteronism in Pregnancy

Table 2. Diagnostic challenges of hyperaldosteronism in pregnancy and puerperium

\begin{tabular}{|c|c|c|}
\hline $\begin{array}{l}\text { During or after } \\
\text { pregnancy }\end{array}$ & Diagnostic clue & Common challenges \\
\hline In pregnancy & Blood pressure & $\begin{array}{l}\text { Mild hypertension can be underdiagnosed because of the physiological blood pressure } \\
\text { reduction due to peripheral vasodilation, relative resistance to angiotensin II, and } \\
\text { competitive inhibition of aldosterone by progesterone }\end{array}$ \\
\hline In pregnancy & Blood pressure & Severe hypertension may be diagnosed as PE, which is usually corrected after delivery \\
\hline $\begin{array}{l}\text { Immediately after } \\
\text { pregnancy }\end{array}$ & Blood pressure & Mild hypertension may be masked by anemia and rapid weight loss \\
\hline In pregnancy & Potassium levels & Physiologic pregnancy-related metabolic acidosis may mask moderate hypokalemia \\
\hline In pregnancy & Potassium levels & $\begin{array}{l}\text { Hypokalemia, without hypertension, may be interpreted as a sign of malnutrition, } \\
\text { hyperemesis, Gitelman or Bartter syndrome, other tubular disorders, and gestational } \\
\text { diabetes on insulin therapy }\end{array}$ \\
\hline In pregnancy & $\begin{array}{l}\text { Renin and } \\
\text { aldosterone }\end{array}$ & $\begin{array}{l}\text { Levels of both hormones are elevated due to the physiological activation of the renin- } \\
\text { angiotensin-aldosterone axis; the ratio is reported as increased, but normal values have not } \\
\text { been established; aldosterone can be reduced in PE; antihypertensive drugs used in } \\
\text { pregnancy may interfere with renin and aldosterone levels }\end{array}$ \\
\hline After pregnancy & $\begin{array}{l}\text { Renin and } \\
\text { aldosterone }\end{array}$ & $\begin{array}{l}\text { The best timing is not established, but testing can reasonably delayed to the } \\
\text { re-establishment of normal volemia }\end{array}$ \\
\hline In pregnancy & Imaging & $\begin{array}{l}\text { US is not sensitive; CT is to be avoided, the use of MRI is not fully recommended and should } \\
\text { whenever possible be postponed until after pregnancy, also due to the lack of the usual } \\
\text { indications for surgical treatment in pregnancy }\end{array}$ \\
\hline After pregnancy & Imaging & $\begin{array}{l}\text { Small adenomas may be difficult to detect; unilateral hyperplasia (PUAH) is considered a } \\
\text { rare disease (Orphanet code: ORPHA: 231580) and may be associated with CT scan showing } \\
\text { normal adrenals }\end{array}$ \\
\hline
\end{tabular}

PE, preeclampsia; US, ultrasound; CT, computed tomography; MRI, magnetic resonance imaging; PUAH, primary unilateral adrenal hyperplasia.

nancy in 6 patients, thus underlining once more how precious pregnancy is for the detection, diagnosis, and care of cardiovascular and kidney disorders.

The ambiguous relationship between PE and pregnancy-induced hypertension (PIH) is also exemplified in the study: 3 cases were labelled as PIH, 7 as superimposed PE, and in all the others, hypertension either persisted or was decompensated in pregnancy [1]. Without going into detail on the challenging concept of superimposed PE, one cannot fail to wonder why a young woman with hypertension had not previously been screened for secondary causes, as we know that the prevalence of "nonessential" hypertension is highest in young, nonobese women; likewise, the delay in reaching a diagnosis after pregnancy is startling.

While to date the Italian Society of Nephrology has been the only scientific society to issue a position statement on the need for follow-up after PE, this case series suggests that PIH probably deserves the same attention, at least in cases in which hypertension persists. In addition, it is clear that we need to discuss who should control the persistence of hypertension, given that nonsymptomatic young mothers are not an easy target once back home with their babies [5].

Furthermore, why was diagnosis so often delayed after pregnancy and why should it be difficult to diagnose primary hyperaldosteronism in pregnancy or immediately after? Two cases recently observed in our ward exemplify these difficulties (Tables 1 and 2). Both patients presented in pregnancy with only 1 diagnostic clue: low potassium levels in 1 patient, who had presented with protracted hyperemesis, and severe hypertension in 


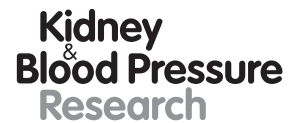

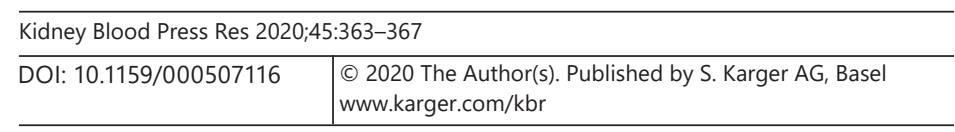

Piccoli and Mannucci: Primary Hyperaldosteronism in Pregnancy

the second patient, who was obese and hypertensive after her first gestation, complicated by hypertension and proteinuria, which were labelled as PE but were probably already a sign of an endocrinopathy. In both, temporary loss to follow-up after delivery retarded diagnosis, even if the diagnosis was suspected during gestation, in one case due to the association between severe hypokalemia and borderline hypertension and in the other because of severe hypertension with occasional hypokalemia at tests performed before pregnancy. Indeed, diagnosis was made later in the presence of severe hypertension and hypokalemia (Table 1).

There are many diagnostic challenges: first of all, in pregnancy, a low potassium level is not always seen as a specific warning by obstetricians, since it may derive from hyperemesis; secondly, the mild acidosis that is often observed in pregnancy increases the serum potassium level, thus masking a mild reduction; thirdly, at least in some settings, taking alimentary supplements rich in proteins, potassium, magnesium, etc., is quite popular in pregnancy, and this may correct a mild potassium deficit (Table 2) [6].

Furthermore, mild hypertension may be masked by the physiological blood pressure reduction that occurs in pregnancy. Conversely, severe hypertension is generally initially interpreted as a hallmark of PE, in particular when it is associated with intrauterine growth restriction; in the absence of severe hypokalemia, no warning bells ring, and in the immediate post-partum period, in particular if there has been significant blood loss, hypertension may once more be masked, to rise shortly afterwards to dangerous levels, as in the cases recently observed by our team (Tables 1 and 2).

Testing for renin and aldosterone during pregnancy does not seem to be a solution. The normal levels of renin and aldosterone for pregnant women are clearly established: the reninangiotensin system is activated and the ratio between aldosterone and renin is increased. Conversely, a low aldosterone level has been associated with PE [7]. Therefore, in part on account of multiple drug interferences and the difficulty of carrying out a pharmacologic washout, renin and aldosterone are rarely tested for in pregnancy (among the most widely used antihypertensive agents, calcium channel blockers reduce aldosterone and increase renin levels, while alpha-methyldopa reduces both).

The best time to perform these tests after delivery has not been established either. Diagnosis is in fact not always straightforward, since the production of aldosterone may be episodic, imaging may be ambiguous, and the ratio may vary over time, thus adding challenge to challenge. Furthermore, the tests are expensive and are often not reimbursed, and this affects compliance, a problem frequently encountered when prescribing multiple evaluations after delivery (Table 2) [8].

While these considerations may explain why primary hyperaldosteronism is probably underdiagnosed after pregnancy, a perhaps simplistic, pragmatic suggestion is to provide an expert (nephrology, internal medicine) consultation after delivery for all patients who present with a hypertensive disorder of pregnancy, whether it is PE or PIH [5].

The evidence on the prevalence of diseases underlying PE is slowly accumulating. The 2 studies we were able to find that deal with the prevalence of preexisting chronic kidney disease lead to a similar estimation of 15-20\% of chronic kidney disease among women who experience one episode of PE $[9,10]$.

We were not able to retrieve studies addressing the prevalence of other secondary causes of hypertension; the series we have commented upon stresses the need for including this workup in the patients who discover hypertension in pregnancy as well as in those in which no workup for early-onset hypertension has been performed. The advantages for the mother's health and the management of future pregnancies are obvious. It is time to reinvest in the study of pregnancy-related morbidity to improve women's future health. 


\section{Disclosure Statement}

The authors declare no conflict of interest.

\section{Funding Sources}

No funding was obtained for this paper. The Centre Hospitalier Le Mans supports English editing and publication fees.

\section{Author Contributions}

Conceptualization: G.B.P.; data curation: G.B.P. and C.M.; writing original draft: G.B.P.; writing, review, and editing: G.B.P. and C.M.

\section{References}

1 Zelinka T, Petrák O, Rosa J, Holaj R, Štrauch B, Widimský J Jr. Primary aldosteronism and pregnancy. Kidney Blood Press Res. 2020;45(2):275-85.

2 Mol BW, Roberts CT, Thangaratinam S, Magee LA, de Groot CJ, Hofmeyr GJ. Pre-eclampsia. Lancet. 2016 Mar; 387(10022):999-1011.

3 Covella B, Vinturache AE, Cabiddu G, Attini R, Gesualdo L, Versino E, et al. A systematic review and metaanalysis indicates long-term risk of chronic and end-stage kidney disease after preeclampsia. Kidney Int. 2019 Sep;96(3):711-27.

4 Piccoli GB, Zakharova E, Attini R, Ibarra Hernandez M, Covella B, Alrukhaimi M, et al. Acute Kidney Injury in Pregnancy: The Need for Higher Awareness. A Pragmatic Review Focused on What Could Be Improved in the Prevention and Care of Pregnancy-Related AKI, in the Year Dedicated to Women and Kidney Diseases. J Clin Med. 2018 Oct; 7(10):E318.

5 Piccoli GB, Cabiddu G, Castellino S, Gernone G, Santoro D, Moroni G, et al.; Kidney and Pregnancy Study Group of Italian Society of Nephrology. A best practice position statement on the role of the nephrologist in the prevention and follow-up of preeclampsia: the Italian study group on kidney and pregnancy. J Nephrol. 2017 Jun;30(3):307-17.

6 Belzile M, Pouliot A, Cumyn A, Côté AM. Renal physiology and fluid and electrolyte disorders in pregnancy. Best Pract Res Clin Obstet Gynaecol. 2019 May;57:1-14.

7 Kilmartin C, Opu T, Podymow T, Dayan N. Primary hyperaldosteronism presenting as persistent postpartum hypertension: illustrative case and systematic review. Obstet Med. 2019 Dec;12(4):190-5.

8 Verdonk K, Visser W, Van Den Meiracker AH, Danser AH. The renin-angiotensin-aldosterone system in preeclampsia: the delicate balance between good and bad. Clin Sci (Lond). 2014 Apr;126(8):537-44.

9 Filali Khattabi Z, Biolcati M, Fois A, Chatrenet A, Laroche D, Attini R, et al. Chronic kidney disease in preeclamptic patients: not found unless searched for-Is a nephrology evaluation useful after an episode of preeclampsia? J Nephrol. 2019 Dec;32(6):977-87.

10 Kattah AG, Scantlebury DC, Agarwal S, Mielke MM, Rocca WA, Weaver AL, et al. Preeclampsia and ESRD: The Role of Shared Risk Factors. Am J Kidney Dis. 2017 Apr;69(4):498-505. 